\title{
PEMBELAJARAN BAHASA ARAB \\ SEBAGAI BAHASA KEDUA \\ (UREGENSI BAHASA ARAB DAN \\ PEMBELAJARANNYA DI INDONESIA)
}

\author{
Nginayatul Khasanah \\ Institut Agama Islam Nahdlatul Ulama (IAINU) Kebumen \\ e-mail:nginayatul.kh@gmail.com
}

\begin{abstract}
Abstrak
Bahasa dan manusia bagaikan dua sisi mata uang yang apabila hilang salah satunya, maka kehidupan ini tidak banyak memberi makna bagi dirinya dan orang lain. Urgensi suatu bahasa dapat dilihat dari fungsinya sebagai ideational, interpersonal, social, dan textual. Bahasa Arab merupakan salah satu bahasa komunikasi dunia dan juga bahasa Agama. Kaitannya dengan bahasa Agama, Indonesia sebagai salah satu Negara dengan mayoritas penduduknya beragama Islam menggunakan bahasa Arab sebagai bahasa kedua. Sebagai bahasa kedua pembelajaran bahasa Arab di Indonesia masih menemukan berbagai problematika. Banyak pembaharuuan dan solusi untuk mengatasinya diantaranya dengan menetapkan tujuan pembelajaran, materi pembelajaran serta pendekatan dan metode pembelajaran yang sesuai dengan kondisi pelajar Indonesia.
\end{abstract}

Kata Kunci: Bahasa Kedua, Urgensi, Pembelajaran

\section{A. Pendahuluan}

Kemajuan ilmu pengetahuan dan teknologi berjalan seiring dengan semakin pesatnya perkembangan dunia informatika. Bahasa sebagai salah satu sarana informasi memegang peranan penting dalam mencatat dan mentransfer berbagai peristiwa baik yang sudah terjadi maupun yang sedang terjadi. 
Bahasa, khususnya bahasa Arab yang digunakan secara luas di dunia ini merupakan bahasa persatuan agama, bahasa persatuan kaum muslimin, yang mempersatukan jiwa mereka, walaupun berbeda-beda kebangsaan, tanah air, serta berlainan bahasa asli. Karena itu, di mana agama Islam berkembang maka di situlah bahasa Arab berkembang pula

Begitu besarnya peran bahasa Arab di berbagai belahan dunia. Isma’il dan Lois Lamya al-Faruqi secara tepat menggambarkan fenomena bahasa ini sebagai bahasa yang menentukan bahasa anggota Liga Arab serta menyumbang lebih dari 40-60 persen kosakata bahasa tersebut. Di samping itu, bahasa Arab merupakan bahasa religius satu milyar Muslim di seluruh dunia, yang diucapkan dalam ibadah sehari-hari. Bahasa ini juga merupakan bahasa hukum Islam, yang setidaknya dalam bidang status pribadi, mendominasi kehidupan semua Muslim. Akhirnya inilah bahasa kebudayaan Islam yang diajarkan di beribu-ribu sekolah di dunia. ${ }^{1}$

Dari gambaran di atas, Roger Trigg secara umum menyatakan bahwa bahasa sangat erat kaitannya dengan kegiatan berpikir sehingga sistem bahasa yang berbeda akan melahirkan pola pikir yang berbeda pula. ${ }^{2}$ Oleh karena itu, pengaruh bahasa Arab terhadap berbagai bahasa pada masyarakat non Arab sangat mempengaruhi dalam cara berpikir dan cara bersikap masyarakat muslim di seluruh dunia. Bahkan seseorang tidak akan menjadi ulama atau ustadz yang profesional jika tidak menguasai bahasa Arab.

Indonesia adalah salah satu negara yang mayoritas penduduknya beragama Islam, otomatis motif keagamaan merupakan alasan yang mendasar untuk mempembelajari bahasa Arab. Oleh karena itu studi bahasa Arab dan Islam di Indonesia, hampir merupakan dua hal yang tidak dapat dipisahkan. Kenyataannya memang menunjukkan bahwa kedua bidang studi tersebut hampir bersamaan. Bahasa Arab dikenal di Indonesia sama dengan dikenalnya agama Islam, atau dengan kata lain bahasa Arab di Indonesia sama tuanya dengan agama Islam.

Tulisan ini berusaha untuk mengungkapkan pentingnya bahasa Arab bagi mayoritas orang Indonesia dan menjadikannya sebagai bahasa kedua dalam

\footnotetext{
1 Ismail dan Lois Lamya Al-Faruqi, Atlas Budaya Islam, terj. Ilyas Hasan, (Bandung: Mizan, 2003), hlm.59.

2 Roger Trigg, Understanding Social Science, (Oxford: Basic Blackwell, 1985), hlm.188.
} 
kaitanyya dengan pembelajaran. Proses pembelajaran tersebut membutuhkan beberapa komponen diantaranya tujuan, materi, pendekatan dan metode pembelajaran agar sesuai dengan peserta didik. Pembelajaran bahasa Arab yang notabene sebagai bahasa Asing tentunya menemukan beberapa problematika.

\section{B. Urgensi Bahasa Arab}

Urgensi suatu bahasa dapat dilihat dari fungsinya yang mempunyai peran penting bagi kehidupan manusia. Ada tiga fungsi bahasa yaitu ideational, interpersonal, social, dan textual. Dari fungsi ini, kehidupan manusia tidak dapat dilepaskan dari bahasa. Bahasa dan manusia bagaikan dua sisi mata uang yang apabila hilang salah satunya, maka kehidupan ini tidak banyak memberi makna bagi dirinya dan orang lain. Oleh sebab itu, penciptaan manusia seiring dengan penciptaan kemampuan berbahasanya, dan hanya manusialah yang memiliki bahasa yang sebenarnya.

Betapa urgensiya bahasa bagi kita. Tanpa bahasa kita tidak dapat berbudaya, tidak dapat berkreasi, dan tidak mempunyai peradaban maju. Hal ini dapat dilihat pada makhluk-makhluk lain, seperti binatang, tumbuh-tumbuhan, planet, dan sebagainya. Kehidupan mereka statis sejak diciptakannya sampai kini.

Di sini akan terlihat bahwa bahasa memberi pengaruh yang kuat kepada masyarakat, karena urgensinya bukan saja sebagai media komunikasi, tetapi juga menjadi modal hajat hidup manusia. Kita tidak berhenti belajar bahasa selama masih ada manusia di muka bumi ini.

Bahasa Arab bagi pembelajar merupakan kebutuhan yang penting, karena ia telah menjadi bahasa agama, bahasa komunikasi resmi antar bangsa, bahasa dunia Islam, bahasa perdagangan, bahasa ekonomi dan perbankkan Islam, bahasa kebudayaan, bahasa ilmu pengetahuan dan teknologi, bahasa hukum, bahasa gaul, dan sebagainya. Hal ini menarik para ahli untuk memperbincangkan dan melakukan studi sebagaimana layaknya bahasa-bahasa yang terkenal lainnya, seperti bahasa Inggris, Preancis, Jerman, Mandarin dan lainnya.

Dalam kajian sosiolinguistik, bahasa setidaknya berhubungan dengan empat hal, (1) bahasa mempengaruhi masyarakat, (2) masyarakat 
mempengaruhi bahasa, (3) masyarakat dan bahasa saling berpengaruh, dan (4) bahasa dan masyarakat tidak saling mempengaruhi. Sebagai contoh, orang-orang yang hebat bahasa Arabnya diperlakukan masyarakat secara terhormat karena memiliki Berkembangnya secara pesat perekonomian, ilmu pengetahuan, peradaban, dan pergaulan masyarakat tutur Arab menyebabkan bahasa Arab tidak lagi berada kemampuan yang lebih dari kebanyakan orang, maka ia memiliki status sosial yang lebih baik, dianggap "orang Siak, ustadz, ulama, pandai mengaji, memiliki pengetahuan agama Islam yang cukup" karena ia memiliki ciri tersendiri dan tampil beda dengan orang lain.

Masyarakat dunia merasakan betapa pentingnya mempembelajari bahasa Arab dan kajian-kajian Timur Tengah. Sejak dahulu sampai kini, bahasa Arab telah dipembelajari oleh masyarakat dunia dan hampir tidak ada universitas di negara maju yang tidak membuka jurusan bahasa Arab.

Dari segi politik, bahasa Arab telah berkembang dan mempengaruhi dunia bagian Timur dan Barat. Di bagian Timur, masyarakat tutur bahasa Arab sangat banyak jumlahnya, mulai dari Marokko, Aljazair, Libia, Republik Persatuan Arab, Sudan, Lebanon, Saudi Arabia, Siria, Yordania, Irak, Iran, Afganistan, Turki, Mesir, dan sebagian wilayah Afrika Utara. Negara-negara ini adalah negara yang tingkat perekonomiannya stabil, kaya, dan berperadaban maju. Kebutuhan negara-negara tersebut terhadap tenaga kerja Indonesia hampir tidak terpenuhi, karena faktor kemampuan berbahasa Arab pada anak-anak bangsa ini lemah.

Krisis ekonomi yang melanda dunia akhir-akhir ini membuat perhatian masyarakat ekonomi melirik pengembangan ekonomi dan perbankan dengan sistem syari'ah. yang diharapkan lebih mempunyai daya tahan dari krisis. Bahkan di Indonesia, hampir-hampir tidak ada bank yang tidak membuka bank syari'ah. Hal ini memberi efek kepada perkembangan dan pertumbuhan kosa kata Arab (mufradat) baru yang berhubungan dengan perekonomian dan perbankan. Maka populerlah istilah muamalah, mudharabah, murabahah, baitul mal wa tamwil, qardhul hasan, ujrah, wakalah, hawalah, kafalah, rahn , shada-qah, zakat, infaq, waqaf, tauliyah, isyrak, wadhiah, tsaman, nasiah, tasharruf, sharf, salam. Semua kosa kata ini berbahasa Arab yang harus dipahami maksud dan konteks pemakaiannya oleh para pembelajar agar tidak 
ketinggalan zaman dan buta makna. Dengan demikian, gengsi bahasa Arab terus berkembang ke arah yang positif dan moderen, karena menjadi bahasa pergaulan antar masyarakat, kaum terpembelajar.

Peranan bahasa Arab dalam kebudayaan dunia dan nasional telah mengambil bagian penting sejak berkembangnya agama Islam di Nusantara pada abad XIII dan sampai saat ini masih dirasakan peranannya secara leksikal maupun semantik. Hal ini terlihat pada berbagai bidang. Misalnya ungkapanungkapan kata sakral atau mantera-mantera yang dipakai oleh masyarakat Indonesia pada upacara perkawinan, khataman, khitanan, dan lain-lainnya yang secara umum menggunakan bahasa Arab.

Bahasa Arab juga sangat berperan dalam karya-karya tulis anak-anak bangsa Indonesia. Banyak buku yang dikarang oleh ustadz atau ulama di Indonesia dengan menggunakan huruf Arab-Melayu, seperti buku Perukunan, dan buku-buku yang berkaitan dengan ibadah, hikayat, sejarah Nabi Muhammad, tasawuf, dan sebagainya.

Dalam bidang kesusasteraan Indonesia pada zaman pujangga lama banyak ditulis dengan huruf Arab-Melayu yang banyak menggunakan katakata yang berasal dari bahasa Arab, maka mempembelajari bahasa Arab bagi pembelajar Indonesia, terutama jurusan sastra Indonesia, merupakan kunci untuk menggali kesusteraan Indonesia lama, karena banyaknya kata-kata Arab yang digunakan atau yang diambil menjadi kata-kata bahasa Indonesia sekarang.

\section{Pembelajaran Bahasa Arab di Indonesia}

Setelah seorang anak memperoleh bahasa pertamanya (B1), maka anak itu akan mengalami proses pemerolehan bahasa kedua (B2) melalui apa yang disebut dengan pembelajaran bahasa. Untuk masalah pembahasan ini ada pakar yang menyebut dengan istilah pembelajaran bahasa (language learning) dan ada juga yang menyebut pemerolehan bahasa (language acquisition) kedua. ${ }^{3}$

3 Dadang Sunendar dan Wasid Iskandar, Strategi Pembelajaran Bahasa, (Bandung: P.T. Remaja Rosdakarya, 2008), hlm.77. 
Istilah pembelajaran bahasa digunakan atas keyakinan bahwa bahasa kedua dapat dikuasai hanya dengan proses belajar dengan cara sengaja dan sadar. Hal ini berbeda dengan penguasaan bahasa pertama atau bahasa ibu yang diperoleh secara alamiah, secara tidak sadar yang dapat diperoleh di dalam lingkungan keluarga.

Sedangkan istilah pemerolehan digunakan atas keyakinan bahwa bahasa kedua merupakan sesuatu yang dapat diperoleh baik secara formal dalam pendidikan maupun informal dalam lingkungan kehidupan. ${ }^{4}$ Berikut perbedaan penggunaan istilah dalam dunia pembelajaran bahasa, di antaranya:

1. اطق اللغة (Bahasa pertama)

Bahasa pertama (B1) adalah bahasa sehari-hari atau bahasa Nasional. Ada juga yang menyebutnya sebagai bahasa Ibu. Sering terjadi kekeliruan dalam memaknai bahasa ibu. Bahasa ibu bukanlah bahasa yang digunakan ibu sejak lahir atau bahasa yang digunakan oleh kedua orang tuanya ketika berbicara (suami istri), tetapi bahasa yang digunakan ketika berkominikasi dengan anaknya sejak lahir atau usia paling dini.

2. غير ناطق اللغة (Bahasa kedua)

Secara umum belajar bahasa yang bukan bahasa pertama (B1) disebut bahasa kedua (B2) atau bahasa asing. Yakni, bahasa yang digunakan oleh orang secara umum dalam masyarakat luas (tetapi bukan bahasa rumah tangga), maupun yang dipakai oleh orang "asing" (yakni di luar lingkungan masyarakat dalam kelompok atau bangsa). ${ }^{5}$

Dapat ditarik kesimpulan bahwa istilah yang tepat dalam dunia pendidikan di Indonesia adalah bahasa Arab sebagai “نَّير ناطق اللغة", sedangkan bahasa Indonesia adalah "ناطق اللغة". Bahasa Arab dapat dikuasai hanya dengan proses belajar yang dilakukan secara sengaja dan sadar, maka tepatlah kiranya istilah yang digunakan adalah "pembelajaran" (language learning).

Ibid.

5 Subyakto Nababan, Sri Utari, Metodolologi Pengajaran Bahasa, (Jakarta: Gramedia Pustaka Utama, 1993), hlm. 3. 
Mengapa bahasa Arab menjadi bahasa kedua dalam dunia pendidikan di Indonesia? Secara historis bahasa Arab mempunyai hubungan erat yang tidak dapat dipisahkan dari dunia pendidikan di Indonesia. Lantas bagaimanakah urgensi bahasa Arab dan pembelajarannya yang efektif, yaitu pembelajaran yang tepat, dengan waktu yang relatif singkat, dan mencapai hasil yang maksimal. bagi para pembelajar di Indonesia. Atas pandangan tersebut, institusi pendidikan baik formal maupun non formal yang berafiliasi keIslaman sudah semestinya menjadikan bahasa Arab sebagai pembelajaran yang diprioritaskan di antara bahasa asing lainnya.

Pembelajaran bahasa Arab, sebagaimana pembelajaran bahasa lainnya merupakan suatu sistem yang melibatkan banyak komponen (tidak berdiri sendiri). Komponen tersebut saling berkaitan dan mempengaruhi berhasil tidaknya pembelajaran bahasa. Di antara komponen-komponen tersebut adalah tujuan, materi, metode, sumber belajar, media pembelajaran, evaluasi hasil belajar. ${ }^{6}$

Di antara berbagai komponen tersebut sebagai berikut:

1. Tujuan Pembelajaran Bahasa Arab

Apapun yang ingin dicapai seseorang dalam mempembelajari bahasa asing, tujuan akhirnya adalah agar ia dapat menggunakan bahasa tersebut baik dengan lisan maupun tulisan secara tepat, fasih dan bebas untuk berkomunikasi dengan orang yang menggunakan bahasa tersebut, dengan kata lain ada empat kemahiran yang harus dicapai, yakni: مهارة الإستماع,

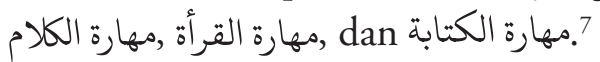

Tentunya menjadi dasar utama sebelum melangkah kepada komponen selanjutanya. Adapun tujuan bahasa asing di Indonesia termasuk bahasa Arab adalah agar siswa atau pembelajar mampu menggunakan bahasa asing secara aktif maupun pasif. ${ }^{8}$

6 Asyrofi, Syamsuddin dkk., Metodologi Pembelajaran Bahasa Arab, (Yogyakarta: Pokja Akademik UIN Sunan Kalijaga, 2006), hlm.18.

7 Sumardi, Muljanto, Pengajaran Bahasa Asing: Sebuah Tinjauan Metodologis, (Jakarta: Bulan Bintang, 1974), hlm.56.

8 Sokah, Umar Asasuddin, Problem Pengajaran Bahasa Arab \& Inggris, (Yogyakarta: Nurcahaya, 1982), hlm.33. 
Tayar Yusuf dan Syaiful Anwar secara garis besar membedakan tujuan pembelajaran menjadi dua macam, yakni tujuan umum dan tujuan khusus. ${ }^{9}$ Tujuan umum dalam pembelajaran bahasa Arab diarahkan agar; (a) pembelajar dapat memahami teks-teks agama (al-Qur'an dan Hadis) sebagai sumber hukum Islam dan ajaran; (b) dan memahami dan mengerti literatur-literatur asli yang ditulis dalam bahasa Arab; (b) pandai berbicara dan mengarang dalam bahasa Arab (c) dapat digunakan sebagai alat pembantu lain (suplementary), dan; (5) membina ahli bahasa yang profesional.

Tujuan pembelajaran bahasa Arab yang dibutuhkan adalah membentuk pembelajar di Indonesia; (1) terampil mendengar dan berbicara (maharah istima'-kalam) dengan topik-topik yang komunikatif dan kontekstual dan, (2) terampil membaca dan menulis bahasa Arab (maharah qira'ah-kitabah), yaitu membaca teks topik-topik tentang sosial keagamaan dan keprodian, serta menulis, yaitu melambangkan huruf/ kata-kata bahasa Arab dengan baik dan benar dalam konteks kebutuhannya hari ini dan ke depan.Tujuan ini terlihat bahwa fokus pembelajaran bahasa Arab untuk berkomunikasi, yaitu pembentukan keterampilan berbahasa; bukan kepada pengetahuan bahasa. Pengetahuan bahasa bersifat terapan; bukan teoritis.

Berdasarkan paparan diatas memang benar bahwa setiap pembelajaran termasuk pembelajaran bahasa Arab harus menetapkan tujuan sebelum pembelajaran berlangsung. Dengan adanya tujuan yang jelas maka pembelajaran diharapkan akan berjalan sesuai dengan batasan-batasan yang ditentukan. Tujuan pembelajaran bahasa Arab tentunya harus disesuaikan dengan situasi serta kondisi peserta didik. Tujuan pembelajaran akan mempengaruhi pada pemilihan materi dan pendekatan serta metode pembelajaran yang akan dilaksanakan.

\section{Materi Pembelajaran Bahasa Arab}

Untuk mencapai tujuan pembelajaran bahasa Arab yang diinginkan tentunya memerlukan sarana yaitu berupa materi pembelajaran. Materi

9 Anwar, Syaiful, dan Tayar Yusuf, Metodologi Pengajaran Agama dan Bahasa Arab, (Jakarta: Raja Grafindo Persada,1997), hlm.190. 
pembelajaran adalah bahan yang digunakan untuk belajar dan yang membantu untuk mencapai tujuan pembelajaran. Untuk mendukung tercapainya suatu tujuan pembelajaran, materi harus dipilih dengan tepat. ${ }^{10}$

Dalam rangka pencapaian tujuan pembelajaran, seorang pengajar dituntut harus pandai dan terampil dalam memberikan materi yang mudah dipahami pembelajar. Pengajar harus betul-betul kompeten dalam bidang pembelajaran tersebut, dan semestinya mengetahui pula texbook mana yang telah memenuhi kriteria yang baik dan tepat untuk disampaikan pada pembelajar. Berkaitan dengan masalah texbook, hendaknya harus disesuaikan dengan kondisi pembelajar yang mempelajarinya dari pengajar yang menjadi pembimbing dalam proses pembelajarannya, sudah seharusnya didasarkan pada tujuan materi pembelajaran yang telah digariskan. ${ }^{11}$

Jika kita amati materi ajar bahasa Arab terdiri atas (1) topik materi ajar dan, (2) desainnya yang menggambarkan kegiatan pembelajarannya. Topik materi ajar bahasa Arab yang efektif adalah topik-topik yang komunikatif dan kontekstual tentang tema keseharian, keagamaan, iptek, dan keprodian.

Sedangkan desain pembelajarannya mencakup: keterampilan mendengar dan berbicara (Istima'-Kalam), di antaranya: (a) Teks Percakapan yang komunikatif dan kontekstual, (b) Mufradat (c) Tadribat (Pelatihan).

Pemilihan materi hendaknya dilakukan dengan selektif dan memenuhi beberapa kriteria diantaranya :

a. Materi atau bahan pelajaran harus relevan terhadap tujuan yang harus dicapai.

b. Materi atau bahan harus balance antara taraf kesulitan dengan kemampuan pembelajar agar dapat menerima dan mengolah bahan itu.

10 Asyrofi, Syamsuddin dkk., Metodologi..., hlm.21.

11 Syamsuddin, Metodologi Pengajaran Bahasa Arab Analisi Texbook Bahasa Arab, (Yogyakarta: Sumbangsih offset, 1988), hlm.4. 
c. Materi dan bahan hendaknya sesuai dengan didaktik yang diikuti.

d. Materi dan bahan harus sesuai dengan pelajaran yang tersedia.

Setidaknya ada empat aspek penting dalam analisis desain materi pembelajaran bahasa, yakni seleksi, gradasi, presentasi, dan repetisi.

a. Seleksi

Tujuan Program bahasa tentu akan mempengaruhi seleksi materi yang akan diberikan dan diajarkan. Seleksi tersebut bisa dilakukan terhadap materi yang akan diberikan, baik seleksi terhadap unsur tata bunyi, kosakata, tata-makna, atau semantika maupun gramatika.

Ada beberapa faktor yang mempengaruhi seleksi materi yang akan diajarkan, di antaranya: (1) Tujuan program pembelajaran bahasa. (2) Tingkat kemahiran pembelajar. (3) Lama program pembelajaran. Pendapat di atas sejalan dengan Mackey, menurutnya ada lima prinsip yang melandasi seleksi, yakni: (1) Tujuan belajar. (2) Tingkat kemampuan belajar. (3) Lama waktu belajar. (4) Pilihan tipe bahasa yang dipelajari. (5) faktor kemungkinan di pelajari.

b. Gradasi

Setelah proses penyelesaian materi selesai dilakukan, maka langkah selanjutnya menyusun materi yang sudah diseleksi tersebut tahap demi tahap, karena materi yang telah diseleksi tersebut tidak mungkin diajarkan sekaligus. Prinsip utama gradasi adalah bahwa setiap pengetahuan datang bertahap dan kemahiran dapat dicapai hanya secara berangsur-angsur.

Salah satu tujuan dari gradasi yang baik adalah untuk menghindari kekacauan. Gradasi dilakukan haruslah disesuaikan dengan tingkat kemampuan pembelajar, bisa urutkan dari tingkat yang mudah kepada tingkat yang sulit.

Mackey mengungkapkan aspek-aspek dalam melakukan gradasi, yakni pengelompokan (grouping) dan pengurutan (gradation). Menurutnya pengelompokan harus didasarkan pada prinsip-prinsip keseragaman, kekontrasan, dan keparalelan. Sedangkan pengurutan 
harus didasarkan pada prinsip psikologi belajar, dari yang umum ke khusus, dari yang ringkas, ke panjang, dari yang sederhana ke kompleks. ${ }^{12}$

Beberapa prinsip yang harus diperhatikan dalam melakukan pengurutan materi, di antaranya:

1. Bentuk yang sama (uniformity) memacu kecepatan belajar sehingga perlu diajarkan bersama-sama.

2. Bentuk-bentuk yang berlawanan (beropoisisi) juga perlu diajarkan bersama-sama, karena secara psikologis akan membuat jelas bentuk-bentuk tersebut.

3. Bentuk-bentuk dan sifatnya paralel jika perlu di kelompokkan, karena akan memberi kejelasan.

4. Kaidah-kaidah umum perlu di ajarkan terlebih dahulu, sebelum kaidah-kaidah yang spesifik.

5. Kaidah-kaidah yang ringkas perlu di ajarkan sebelum kaidah yang berpanjang-panjang.

6. Kaidah-kaidah yang sederhana di ajarkan terlebih dahulu sebelum kaidah yang kompleks.

7. Kaidah yang teratur di ajarkan terlebih dahulu sebalum kaidah yang menyimpang (pengecualian).

8. Kaidah-kaidah yang paling berguna (dibutuhkan) oleh pembelajar diajarkan terlebih dahulu dibandingkan dengan kaidah yang kurang berguna (prinsip kebergunaan).

9. Urutan penyajian juga harus mempertimbangkan urutan pemerolehan.

c. Presentasi

Setelah melewati tahap seleksi dan gradasi selanjutnya adalah tahap presentasi, yakni bagaimana agar materi yang telah diseleksi dan dikelompokkan tersebut dapat disampaikan dan dipahami oleh

12 Azhar Arsyad, Bahasa Arab dan Metodologi Pembelajarannya, (Yogyakarta: Pustaka Pembelajar, 2004), hlm. 402. 
pembelajar. Hal ini tentu saja tidak hanya bergantung dari tehnik mengajar yang dianut suatu metode tetapi juga tehnik mengajar yang dikuasai guru beserta kemampuanya untuk berimajinasi.

Pengajaran bahasa menyangkut ekspresi dan isi. Dari segi ekspresi ada dua hal yang perlu diperhatikan, yaitu apa yang disebut staging dan demonstration. Yang dimaksud staging di sini ialah jumlah bentuk bahasa yang termasuk dalam suatu metode dan jumlah pembagiannya menjadi tahap-tahap, urutan penyajiannya antara satu bagian dan bagian lainnya, serta pembagiannya ke dalam unit atau satuan presentasi. Sedangkan yang dimaksud demonstration ialah teknik-teknik yang digunakan oleh suatu metode untuk menyajikan atau menyampaikan materi pelajaran.

Akan tetapi dalam penelitian ini yang ingin ditekankan penulis dari aspek presentasi adalah cara mengkomunikasikan materi kepada pembelajar bahasa, yaitu apa yang tampak pada halaman-halaman buku. Guru harus mempunyai kemampuan dalam melakukan presentasi materi. Selain itu dengan menggunakan metodologi yang tepat maka presentasi akan menghasilkan materi yang baik. Dari uraian di atas dapat digambarkan:

1. Materi yang baik--- presentasi guru jelek, maka akan memperoleh hasil yang tidak baik.

2. Materi yanhg jelek---presentasi guru baik, maka akan memperoleh hasil yang jelek.

3. Materi baik---presentasi guru baik, maka akan memperoleh hasil yang baik.

d. Repetisi

Sudah dijelaskan sebelumnya bahwa tujuan akhir dari pembelajaran bahasa adalah agar pembelajar bahasa bisa menggunakan bahasa tersebut dengan baik secara lisan maupun tulisan. Dengan kata lain menguasai keempat maharah, yaitu menyimak, berbicara, membaca dan menulis. 
Bahasa adalah rangkaian kebiasaan yang saling berhubungan. Suatu perbuatan akan menjadi kebiasaan kalau perbuatan tersebut terus diulang-ulang sampai beberapa kali. Dalam belajar bahasa yang dibentuk tentunya kebiasaan yang baik. Repetisi dalam pembelajaran bahasa merupakan penajaman yang meliputi: (1) menyimak; (2) berbicara; (3) membaca; (4) menulis.

Selain dua komponen di atas yaitu tujuan dan materi pembelajaran sebenarnya adaa komponen guru (pengajar bahasa) akan tetapi dalam kesempatan kali ini komponen guru belum dibahas dalam tulisan ini. Komponen lain dan yang tidak kalah pentingnya dalam proses pembelajaran bahasa yakni pendekatan dan metode pembelajaran yang digunakan.

3. Pendekatan dan Metode Pembelajaran Bahasa Arab

Bahasa Arab adalah entitas terdekat dan sekaligus terjauh. Begitu dekat, karena ia senantiasa hadir dalam keseharian kita (melalui bahasa shalat, do'a dan lain-lain). Begitu jauh, karena ia kadang menampakkan wajah kesulitannya untuk dipelajari. Bahasa Arab sebagai objek yang dipelajari mempunyai karakteristik yang berbeda dengan bahasa Indonesia sebagai bahasa Ibu. Oleh karena itu pendekatan pembelajaran sangat menentukan proses implementasi metode pembelajaran yang berlangsung di kelas. Pendekatan merupakan asumsi atau cara pandang secara umum mengenai bahasa Arab. Sesuai dengan tujuan di atas, pendekatan pembelajaran yang efektif mencakup empat pendekatan, yaitu pendekatan humanistik, komunikatif, kontekstual, dan struktural.

(1) Pendekatan humanistik melihat bahwa pembelajaran bahasa Arab memerlukan keaktifan pembelajarnya, bukan pengajar. Pembelajarlah yang aktif belajar bahasa dan pengajar berfungsi sebagai motivator, dinamisator, administrator, evaluator, dan sebagainya. Pengajar harus memanfaatkan semua potensi yang dimiliki pembelajar.

(2) Pendekatan komunikatif melihat bahwa fungsi utama bahasa adalah komunikasi. Hal ini berarti materi ajar bahasa Arab harus materi yang praktis dan pragmatis, yaitu materi ajar terpakai dan 
dapat dikomunikasikan oleh pembelajar secara lisan maupun tulisan. Materi ajar yang tidak komunikatif akan kurang efektif dan membuang waktu saja.

(3) Pendekatan kontekstual melihat bahasa sebagai suatu makna yang sesuai dengan kebutuhan pembelajar dan setingnya. Di sini, rancangan materi ajar harus berdasarkan kebutuhan lembaga, kebutuhan pembelajar hari ini dan ke depan.

(4) Pendekatan struktural melihat bahwa pembelajaran bahasa sebagai hal yang formal. Oleh sebab itu, struktur bahasa (qawaid) harus mendapat perhatian dalam merancang materi ajar. Namun struktur harus fungsional agar komunikatif dan praktis. Qawaidlgrammar yang tidak praktis dan tidak komunikatif dalam pembelajaran bahasa Arab telah gagal membentuk pembelajar terampil berbahasa, bukan saja bahasa Arab tetapi juga bahasa Inggris.

Selanjutnya metode pembelajaran bahasa Arab dapat dimaknai sebagai cara atau jalan yang dilalui untuk mencapai tujuan pendidikan. Dalam hal ini tujuan pembelajaran bahasa Arab. Menurut Ahmad Fuad Effendi, metode adalah rencana menyeluruh penyajian bahasa secara sitematis berdasarkan pendekatan yang ditentukan. ${ }^{13}$ Senada dengan defenisi Abu Bakar Muhammad, ia menegaskan bahwa metode adalah jalan atau cara yang ditempuh oleh guru untuk menyampaikan materi dalam pembelajaran. ${ }^{14}$

Di antara metode pembelajaran bahasa Arab adalah Direct Methodl, The Aural Oral Approach/الطريقة السمعية السفويقة المباشرة Elektik/الطريقة الانتقائية, dan masih banyak lagi metode-metode yang lainnya. Metode yang digunakan tersebut disesuaikan dengan tujuan kemahiran berbahasa yang akan dicapai. Sebagaimana kita mengetahui bahwa bahasa Arab mempunya empat kemahiran berbahasa serta komponen bahasa. Kemahiran berbahasa tersebut yaitu kemahiran

13 Ahmad Fuad Effendy, Metodologi Pengajaran Bahasa Arab, (Malang: Misykat, 2005), hlm.6.

14 Abu Bakar, Muhammad, Metode Khusu Pengajaran Bahasa Arab, (Surabaya: Usaha Nasional, 1990), hlm.8. 
mendengar (maharah al-Istima), kemahiran Berbicara (Maharah alkalam), kemahiran membaca (maharah al-Qira'ah), dan kemahiran menulis (Maharah al-Kitabah). Sedangkan komponen bahasa diantaranya adalah nahwu dan sharf. Dengan demikian metode yang digunakan juga harus sesuai dengan kemahiran berbahasadan komponen bahasa yang menjadi pokok pembelajaran. Dengan demikian dalam pembelajaran bahasa tidak hanya diperlukan satu metode saja.

\section{Penutup}

Bahasa kedua merupakan bahasa yang dipelajari oleh penutur asli yang telah mempelajari bahasa pertama sebagai bahasa Ibu. Bahasa Arab bagi orang Indonesia merupakan bahasa kedua. Bahasa arab bagi orang indonesia begitu lekat sebagai bahasa Agama Islam. Umat Islam khususnya sangatlah membutuhkan bahasa Arab disamping sebagai salah satu sarana penunjang ibadah juga untuk memperdalam ilmu agama dengan rujukan bahasa Arab.

Bahasa Arab yang mempunyai karakteristik berbeda dengan bahasa Indonesia baik dari segi bentuk huruf dan pengucapannya dalam proses pembelajarannya menemukan beberapa problematika. Problematika tersebut bisa diminimalisir dengan adanya tujuan pembelajaran yang jelas. Tujuan pembelajaran tersebut akan mempengaruhi materi yang akan dipelajari. Selain pemilihan materi yang sesuai, dilanjutkan dengan pengorganisasian materi pada tiap tahapnya. Setelah ada tujuan dan materi pembelajaran tentunya dalam implementasi pembelajaran di kelas membutuhkan pendekatan yang menjadi acuan daalam pemilihan penerapan metode pembelajaran.

\section{Daftar Pustaka}

Anwar, Syaiful, dan Tayar Yusuf, 1997, Metodologi Pengajaran Agama dan Bahasa Arab, Jakarta: Raja Grafindo Persada.

Arsyad,Azhar, 2004, Bahasa Arab dan Metodologi Pembelajarannya, Yogyakarta: Pustaka Pembelajar

Asyrofi, Syamsuddin dkk., 2006, Metodologi Pembelajaran Bahasa Arab, Yogyakarta: Pokja Akademik UIN Sunan Kalijaga. 
Effendi, Fuad, 2005, Ahmad Metodologi Pengajaran Bahasa Arab, Malang: Misykat.

Ismail, Al-Faruqi, dan Lois Lamya, 2003, Atlas Budaya Islam, terj. Ilyas Hasan, Bandung: Mizan.

Muhammad,Abu Bakar, 1990, Metode Khusu Pengajaran Bahasa Arab, Surabaya: Usaha Nasional.

Nababan, Subyakto, Sri Utari,1993,Metodolologi Pengajaran Bahasa, Jakarta: Gramedia Pustaka Utama.

Sunendar, Dadang dan Wasid Iskandar,2008, Strategi Pembelajaran Bahasa, Bandung: P.T. Remaja Rosdakarya.

Sokah, Umar Asasuddin,1982, Problem Pengajaran Bahasa Arab \& Inggris, Yogyakarta: Nurcahaya.

Sumardi, Muljanto,1974, Pengajaran Bahasa Asing: Sebuah tinjauan Metodologis, Jakarta: bulan Bintang.

Syamsuddin, 1988, Metodologi Pengajaran Bahasa Arab Analisi Texbook Bahasa Arab, Yogyakarta: Sumbangsih offset.

Trigg,Roger, 1985, Understanding Social Science, Oxford: Basic Blackwell. 